\title{
Strong Wind Speed Events over Antarctica and Its Surrounding Oceans
}

\author{
LEJIANG YU \\ State Oceanic Administration Key Laboratory for Polar Science, Polar Research Institute of China, Shanghai, China \\ SHIYUAN ZHONG \\ Department of Geography, Environment and Spatial Sciences, Michigan State University, East Lansing, Michigan
}

(Manuscript received 6 December 2018, in final form 4 March 2019)

\begin{abstract}
Strong wind events (SWEs) over Antarctica and its surrounding oceans are investigated using gridded surface wind data from the ERA-Interim for the 1979-2017 period. Throughout the year, SWEs are more prevalent over the coastal region of East Antarctica where mean surface wind speeds are also higher. The occurrences of SWEs appear to be accompanied by positive anomalies in surface temperature and negative (positive) anomalies in mean sea level pressure related to cyclone (anticyclone) activity over the Ronne and Ross Ice Shelves and coastal regions (the inland areas of East Antarctica). The interannual variability of the SWE occurrences appears to be related to the southern annular mode (SAM) and, to a lesser degree, ENSO. The trends of SWE in the recent four decades exhibit considerable regional variations that are consistent with the trends in seasonal mean wind speed and surface air temperature, and can be largely explained by the variations in the sea level pressure trends across the region.
\end{abstract}

\section{Introduction}

Strong wind events (SWEs) are a notable feature of the Antarctic climate system, especially in the Antarctic coastal region. These SWEs play an important role in atmospheric circulations at the high southern latitudes (Parish and Cassano 2001). SWEs can influence the heat budget of the Antarctic troposphere (van Lipzig et al. 2002; van As et al. 2007). Blowing snow as a result of SWEs can redistribute regional precipitation. Déry and Yau (2002) found that each year an average of $29 \mathrm{~mm}$ of snow-water equivalent over Antarctica, which accounts for about $20 \%$ of its annual precipitation, is removed by blowing snow. Anomalous northerly and westerly wind events over the Amundsen Sea Embayment are favorable for the thinning of ice shelves there from above and below, respectively (Deb et al. 2018). Le Quéré et al. (2007) noted that an observed increase in Southern Ocean winds has weakened the ability of the ocean to act as a sink for $\mathrm{CO}_{2}$. While in general SWEs are considered beneficial for wind energy, extreme cases can damage wind turbines. Extreme SWEs can also pose threat to the

\footnotetext{
Corresponding author: Shiyuan Zhong, zhongs@msu.edu
}

safety of crews and infrastructures at the Antarctic stations.

The primary component of SWEs in Antarctica is a katabatic flow that develops when strong radiative cooling during winter months produces negative buoyancy, driving cold, dense air to flow rapidly down the sloping terrain of Antarctica. Over the coastal region, pressure gradient generated by synoptic forcing can enhance the strengths of katabatic winds (Powers et al. 2003). Topography may also modify near-surface winds at local and regional scales (Monaghan et al. 2005). An example of orographic influence is the barrier winds occurring sometimes over the northwestern Ross Ice Shelf (O'Connor et al. 1994; Steinhoff et al. 2009) and the western Weddell Sea (Kottmeier and Hartig 1990) as a result of blocking of flows by mountain barriers. The barrier winds are also influenced by synoptic systems (O'Connor et al. 1994; Steinhoff et al. 2009). Hence, the formation of SWEs results from a complex interaction among large-scale katabatic winds, synoptic flows, and local terrain-induced circulations.

A number of studies on the SWEs over Antarctica are found in the literature. Many of these studies (Murphy and Simmonds 1993; Holmes et al. 2000; Turner et al. 2001; Adams 2005; Speirs et al. 2010; Nigro et al. 2012; 
Orr et al. 2014; Chenoli et al. 2015; Tomikawa et al. 2015) focused on individual cases and their results provided insight into the structure and evolution of SWEs and the underlying physical mechanisms. A few studies analyzed climatology and trend of SWEs, but these analyses were confined to a single station (Chenoli et al. 2013) or a dozen locations (Turner et al. 2009) with limited observational data.

The current study extends previous site-based climatological analyses of SWEs spatially to cover the entire Antarctica and the surrounding oceans and temporally to encompass multiple decades by using long-term gridded reanalysis data. The study documents the regional and seasonal variations of the SWE occurrences and examines interannual variability and trends. The study also explores potential connections between the SWE variability and changes in large-scale circulations.

\section{Dataset and methods}

\section{a. Dataset and SWE definition}

The domain of the study encompasses the entire region south of $60^{\circ} \mathrm{S}$ (Fig. 1). The SWEs in the domain are determined using gridded surface wind speed data from the European Centre for Medium-Range Forecasts (ECMWF) interim reanalysis (ERA-Interim; Dee et al. 2011). Produced using a 12-hourly 4D-Var assimilation system, (Rabier et al. 1998; 2000), ERA-Interim is an improvement over the earlier reanalysis (ERA-40; Uppala et al. 2005). Particularly, there is a $14 \%$ decrease in the mean absolute error of the Antarctic surface winds, relative to ERA-40 (Rodrigo et al. 2013), due likely to the assimilation of atmosphere motion vectors (AMVs) derived from next-generation geostationary satellites and Challenging Minisatellite Payload (CHAMP) global positioning system (GPS) radio occultation data from University Corporation for Atmospheric Research (UCAR), in combination with improved quality control and data selection procedures (Dee et al. 2011). In this study, a strong wind event is simply defined as the $10-\mathrm{m}$ wind speed $\geq 10 \mathrm{~m} \mathrm{~s}^{-1}$. The $10 \mathrm{~m} \mathrm{~s}^{-1}$ wind speed threshold value is chosen following several previous studies, including those of King and Turner (1997), who used $10 \mathrm{~m} \mathrm{~s}^{-1}$ as the threshold for blowing snow, Birnbaum et al. (2006) and van As et al. (2007), who utilized $10.8 \mathrm{~m} \mathrm{~s}^{-1}$ as the criterion for a SWE at the Kohnen station, and Chenoli et al. (2013), who chose Beaufort scale $6\left(11.3 \mathrm{~m} \mathrm{~s}^{-1}\right)$ as the SWE threshold at McMurdo station.

The SWE criterion is applied to the $10-\mathrm{m}$ wind speeds at every grid point four times per day for the period 1979-2017. The original wind speed data have a horizontal resolution of $80 \mathrm{~km}$, which are interpolated

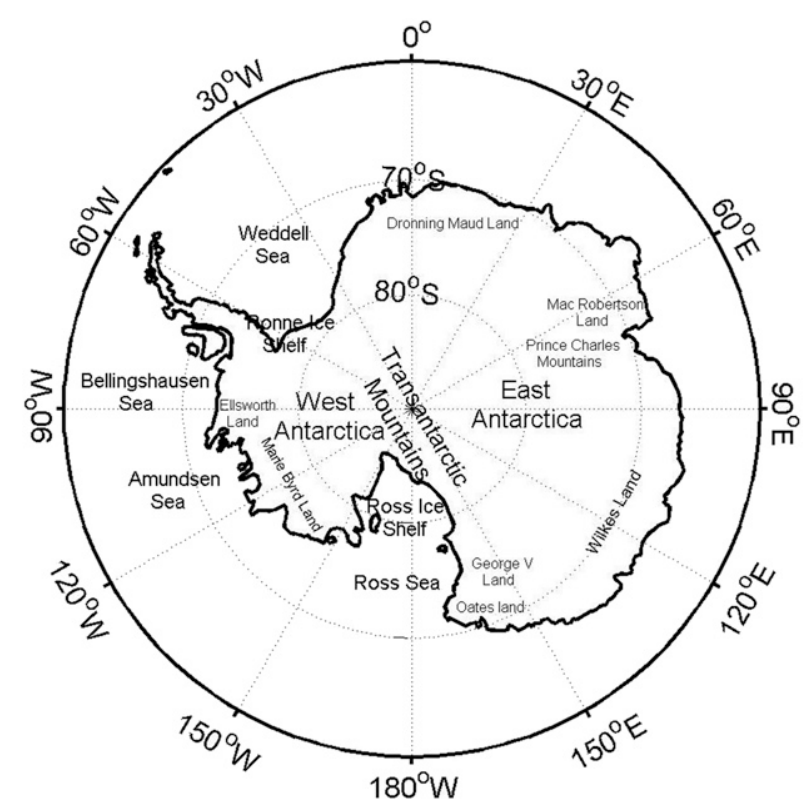

FIG. 1. Map of Antarctica showing the main geographic features.

onto a $0.4^{\circ}$ latitude $\times 0.4^{\circ}$ longitude grid before the criterion is applied. If the criterion is met at all four times of a day, it is considered four events instead of one daily event. This is likely to double count the number of SWE events that are longer than $6 \mathrm{~h}$ while missing some events that are shorter than $6 \mathrm{~h}$. Since SWE events in Antarctica tend to persist over periods longer than $6 \mathrm{~h}$, it is likely that the number of SWE events is overestimated using the current method. This bias, however, is unlikely to influence the results of the current analysis, which is focused on variability. Other atmospheric variables used in the current analyses, such as $500-$ and $850-\mathrm{hPa}$ geopotential heights and winds, are also derived from ERA-Interim.

\section{b. Analysis methods}

Linear trends in SWE occurrences are determined by the least squares method (Wilks 2011). The relationship between the changes in SWE occurrences and known climate modes is examined through linear regression and the statistically significant relationship is identified via the Student's $t$ test. The same approach was used in a similar study before (Yu et al. 2017). The climate modes examined include the southern annular mode (SAM) represented by the SAM index and the eastern and central Pacific El Niño and La Niña represented by the Niño-3 index and Niño-4 index, respectively, all of which are downloaded from the Climate Prediction Center (https://www.cpc.ncep.noaa.gov/). The austral autumn, winter, spring, and summer refer to March-May (MAM), June-August (JJA), September-November 

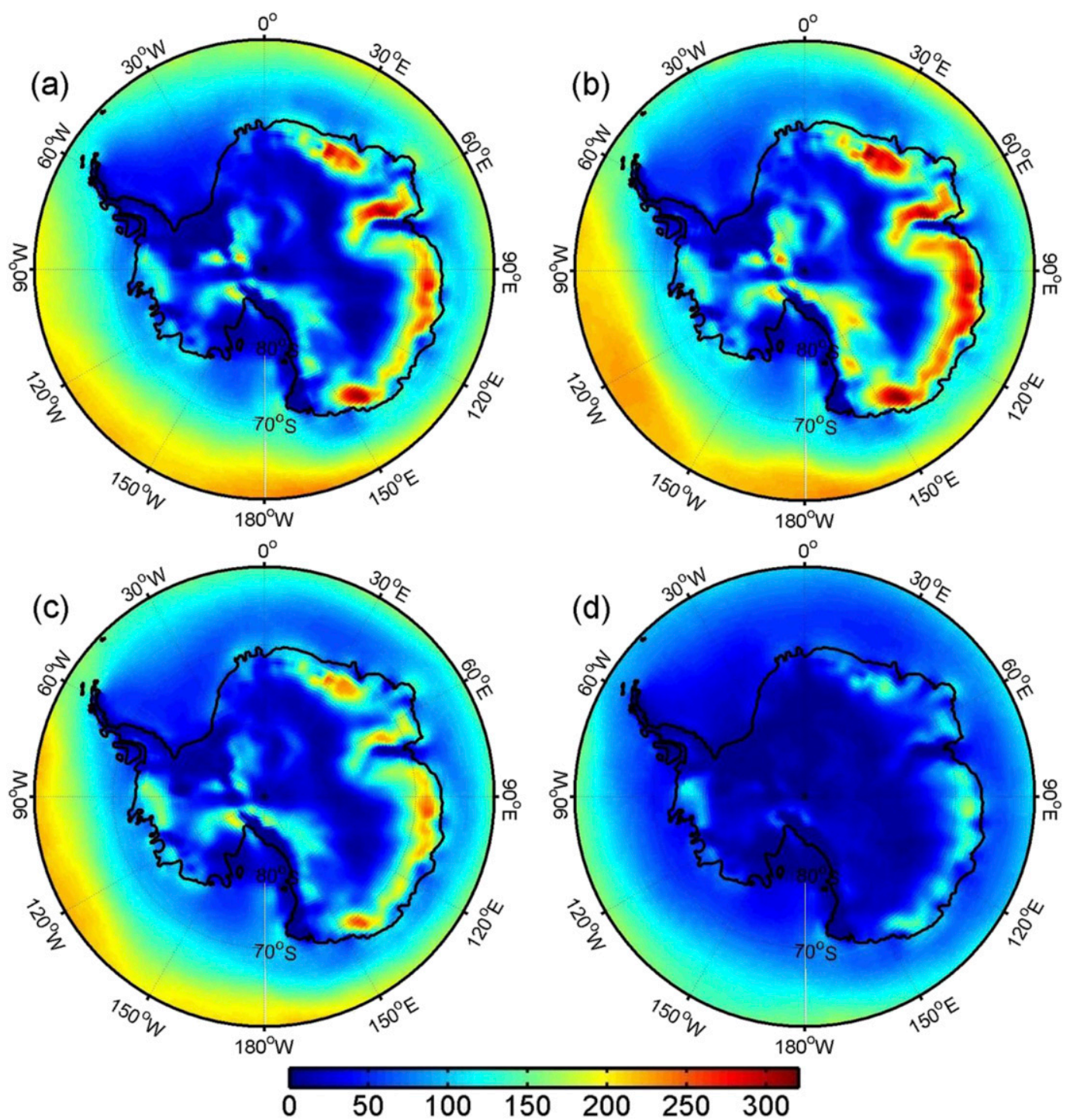

FIG. 2. The average number of strong wind events at each grid point from 1979 to 2017 over the Antarctic continent and its surrounding seas using the criterion of the wind speed $\geq 10 \mathrm{~m} \mathrm{~s}^{-1}$ for (a) austral autumn (MAM), (b) austral winter (JJA), (c) austral spring (SON), and (d) austral summer (DJF).

(SON), and December-February (DJF), respectively and the seasonal index values are calculated by averaging the monthly indices over the three months in each season.

\section{Results}

\section{a. Spatial and seasonal distribution of SWE occurrences}

We first examine the spatial and seasonal variations of SWE occurrences. For a given season, the average number of SWE occurrences, or the climatology, at each grid point is represented by the number of occurrences in that season each year averaged over the
38 years in the study period. The spatial patterns of the average number of SWE occurrences for each season are shown in Fig. 2. There are considerable regional differences in the SWE occurrences and the pattern of the differences is nearly the same throughout the year. The magnitude of the spatial variability is much smaller in summer compared to the other seasons. For all seasons, SWEs are most common over the coastal region of East Antarctica, the west of the Transantarctic Mountains, and the southern Pacific Ocean, and least frequent in the interiors of East Antarctica, the Ronne Ice Shelf, and the Ross Ice Shelf. Among the three regions where SWEs are more common, the highest number of SWEs is found over the coastal regions of 

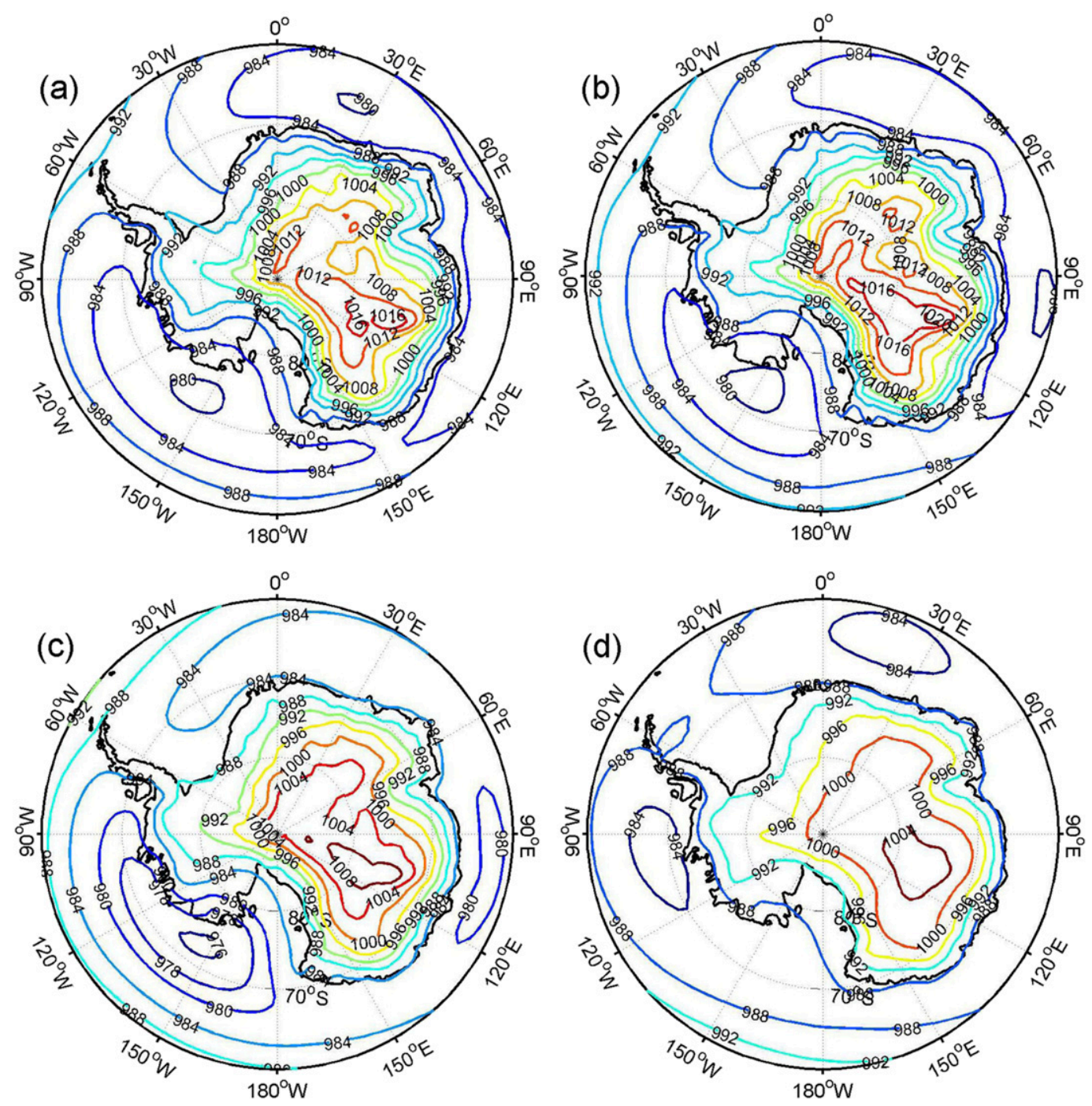

FIG. 3. The average of 38-yr seasonal mean sea level pressure (MSLP) (hPa) for (a) austral autumn, (b) austral winter, (c) austral spring, and (d) austral summer during 1979-2017.

East Antarctica where high pressure over land and low pressure over ocean lead to a strong pressure gradient and thus strong winds (Fig. 3). The strong pressure gradient results from a combination of terrain-induced katabatic force and synoptic-scale force (Turner et al. 2009). The katabatic force dominates over the steeper costal slopes (Parish and Cassano 2003) and is comparable to synoptic-scale force over the gentle inland slopes (van den Broeke and van Lipzig 2003). The frequent SWEs over the west of the Transantarctic Mountains are related to a strong pressure gradient between high pressure inland and the Amundsen low (Fig. 3) and the interaction between the katabatic winds and the low pressure systems (Chenoli et al. 2015). Barrier winds and mountain waves also contribute to the occurrences of SWEs in this region (Steinhoff et al.
2008). The occurrences of SWEs over the southern Pacific Ocean result from the strong pressure gradient over the northern part of the Amundsen low (Fig. 3). The small number of SWEs over inland of East Antarctica, the Ronne Ice Shelf, and the Ross Ice Shelf coincide with relatively weak pressure gradients in these regions (Fig. 3). Although the spatial pattern appears to be independent of seasons, the number of the occurrences show pronounced seasonality, particularly in regions that exhibit high frequencies of SWEs. SWE are much more frequent in austral autumn and winter, and least frequent in summer. Averaging across the entire domain, the number of SWEs are 97.3, 82.4, and 77.3 for austral winter, autumn, and spring, respectively, and drops by nearly half to $41.2 \mathrm{in}$ austral summer. 

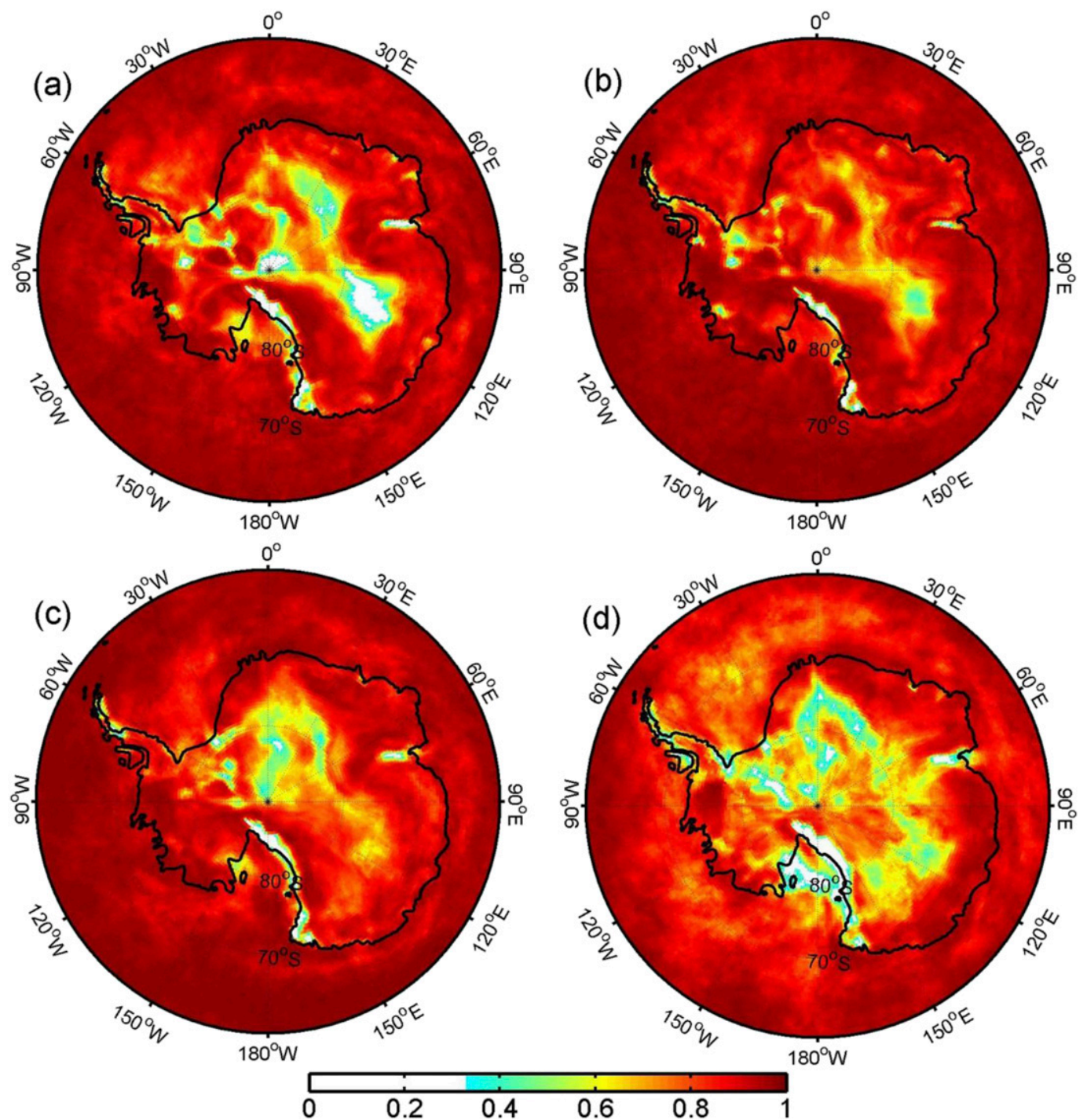

FIG. 4. Correlations between seasonal mean wind speed and the number of SWE occurrences over the 1979-2017 period for (a) austral autumn, (b) austral winter, (c) austral spring, and (d) austral summer. Trends at each grid point are removed prior to the correlation calculation. Only statistically significant correlation coefficients at the above $95 \%$ confidence level are shown.

Next, we examine the relationship between SWEs and seasonal mean wind speeds (Fig. 4). As expected, a positive correlation exists between the number of SWEs and the seasonal mean wind speed everywhere in the domain. For the majority of the domain, the correlation coefficients are greater than 0.8 , suggesting that SWEs are more frequent in a season when seasonal mean winds are stronger over the 38-yr study period. The correlation is statistically significant nearly everywhere except for several small areas in the interiors of East Antarctica, the Transantarctic Mountains, Oates Land, and the Prince Charles Mountains. In addition to these areas, the correlation is also insignificant over the
Ross Ice Shelf for austral summer, where both the mean wind speed and the number of SWE occurrences are lower.

\section{b. Synoptic environments associated with SWES}

Previous station-based studies have shown that many of the SWEs at some stations are associated with positive surface temperature and negative mean sea level pressure (MSLP) anomalies (Turner et al. 2009; Chenoli et al. 2015). To determine if these relationships found at some stations also apply to other locations in Antarctica, or the finding can be extended from local to regional scale, we examine surface and upper-air atmospheric 

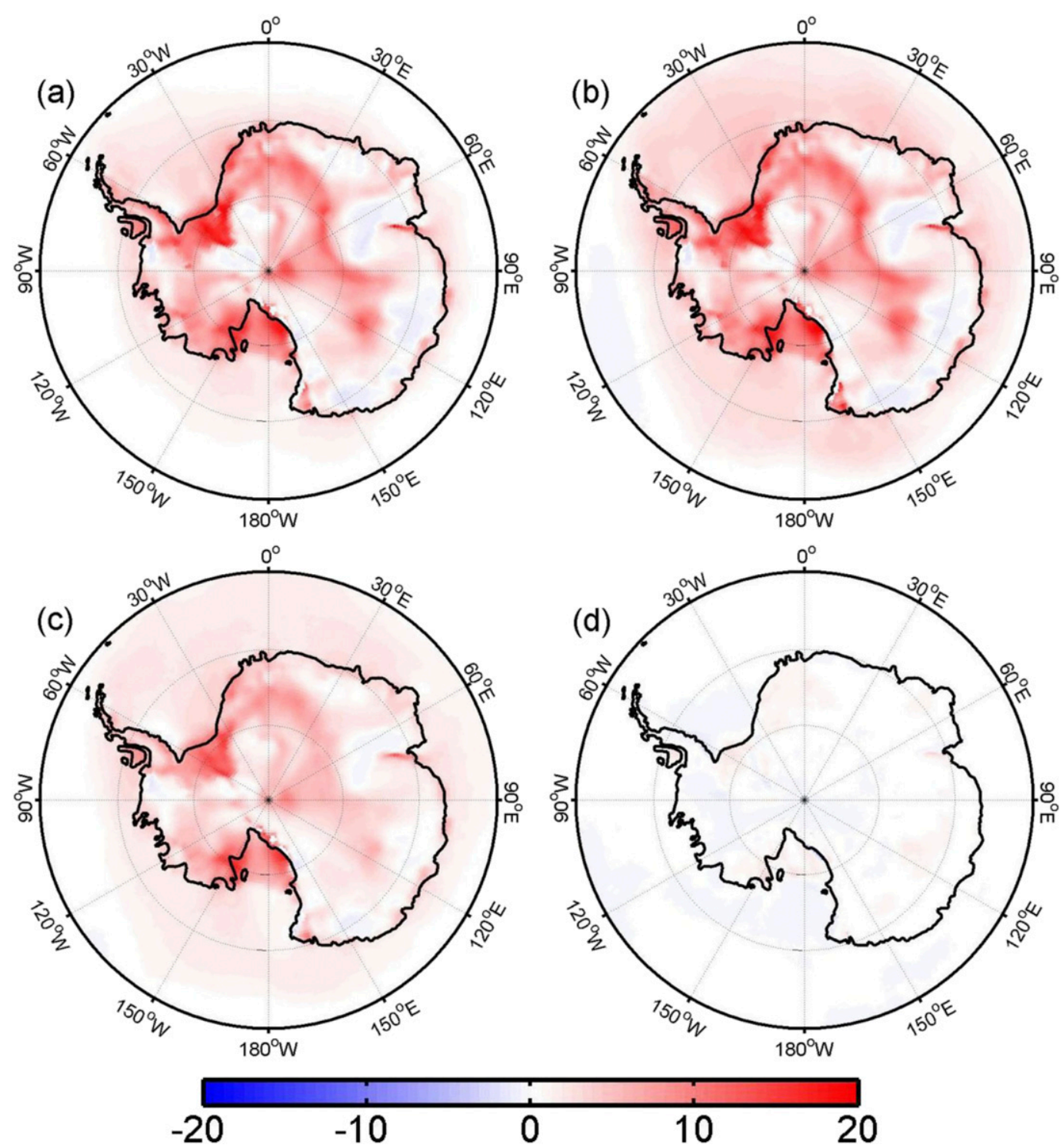

FIG. 5. Averaged surface air temperature anomaly $\left({ }^{\circ} \mathrm{C}\right)$ at each grid point during SWEs for (a) austral autumn,

(b) austral winter, (c) austral spring, and (d) austral summer.

conditions accompanying SWEs by making composites of anomalous surface temperature, MSLP, and 500-hPa potential height at each grid point over all the SWEs (Figs. 5-7). Throughout the year except for austral summer, SWEs appear to be associated with positive surface temperature anomalies (Fig. 5). The warming over West Antarctica and coastal regions corresponds to lower MSLP (Fig. 6). The strong pressure gradient between low pressure related to mesoscale cyclones in the surrounding oceans and some of the coastal areas and high pressure over inland regions transports warmer air from lower latitudes into higher latitudes. The warm surface air advection also helps weaken or even break down temperature inversions and reduce katabatic winds, which may contribute to positive temperature anomalies.

Over the inland of East Antarctica, positive temperature anomalies are consistent with positive $500-\mathrm{hPa}$ geopotential height (Figs. 5 and 7). According to potential vorticity conservation, anticyclones penetrate more easily into the inland plateau compared to cyclones. The warm advection toward the inland of East Antarctica on the western side of a strong pressure center leads to warming at the grid points there (Turner et al. 2009). Higher pressure over East Antarctica is in accordance with lower temperature at areas such as Wilkes and Oates Lands. Anticyclones may increase the pressure gradient caused by katabatic forcing, which 

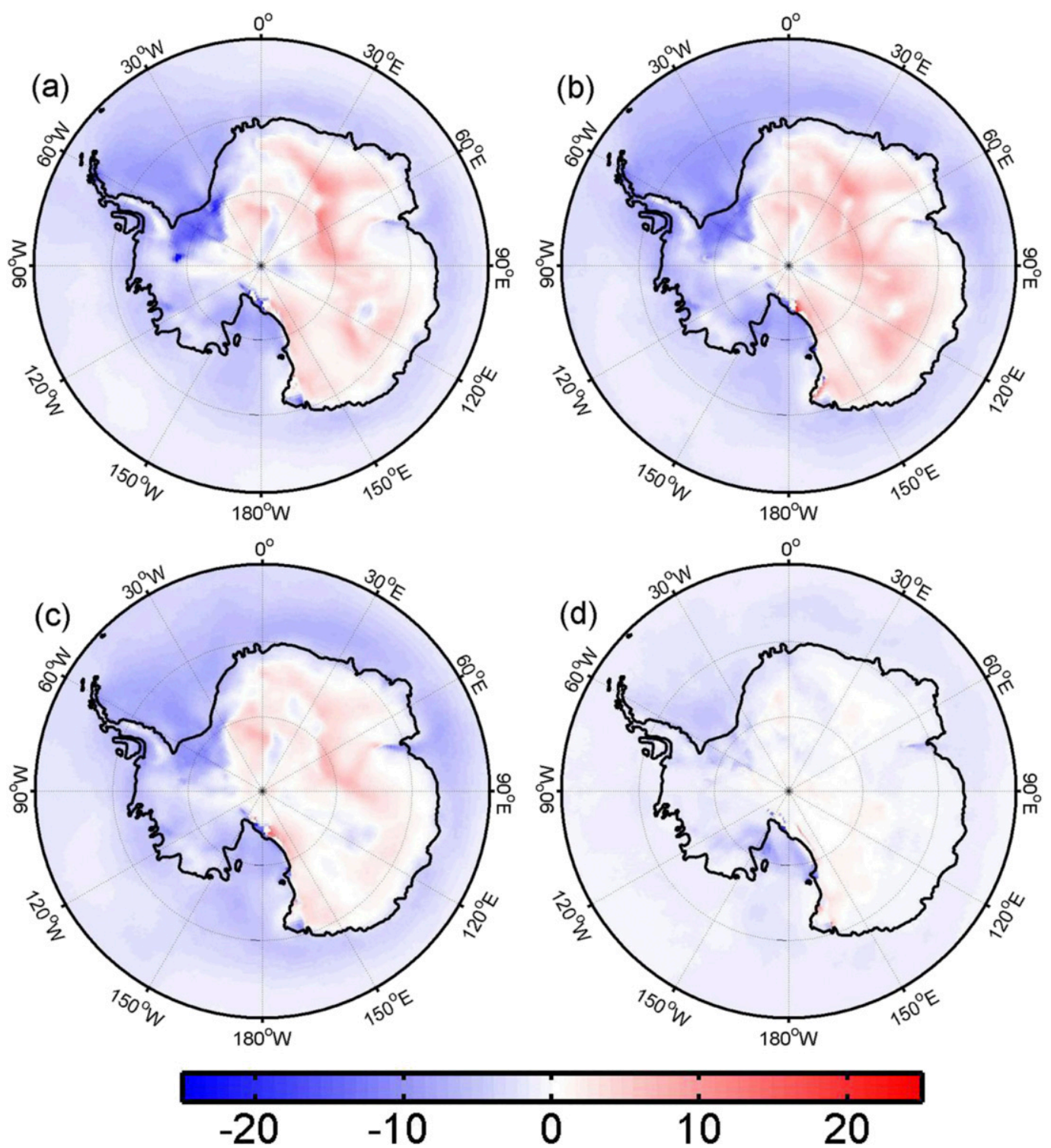

FIG. 6. As in Fig. 5, but for MSLP (hPa).

results in stronger temperature inversion and lower surface temperature on the eastern side of the anticyclones. But the magnitudes of negative temperature anomalies are smaller than those of positive temperature anomalies. Over Ellsworth Land and the Ronne Ice Shelf of West Antarctica, positive temperature anomalies correspond to negative 500-hPa geopotential height anomalies relating possibly to cyclone activity.

In austral summer, the magnitudes of anomalous surface temperature, MSLP, and 500-hPa geopotential height related to SWEs are much smaller compared to other seasons (Figs. 5d, 6d, and 7d). The positive surface temperature anomalies over the Ronne and Ross Ice Shelves and Marie Byrd Land are consistent with the negative MSLP and 500-hPa height anomalies and the associated anomalous northerly wind and temperature advections induced by the anomalous cyclones. The positive surface temperature anomalies over East Antarctica are related to anomalous anticyclones. The temperature anomalies are negative over the Ross and Weddell Seas and Ellsworth Land due possibly to cold air advection by southerly anomalous winds associated with passing cyclones (Fig. 6d).

\section{c. Interannual variability}

We proceed to examine the interannual variability of the seasonal number of SWE occurrences and its possible connection to changes in large-scale atmospheric 

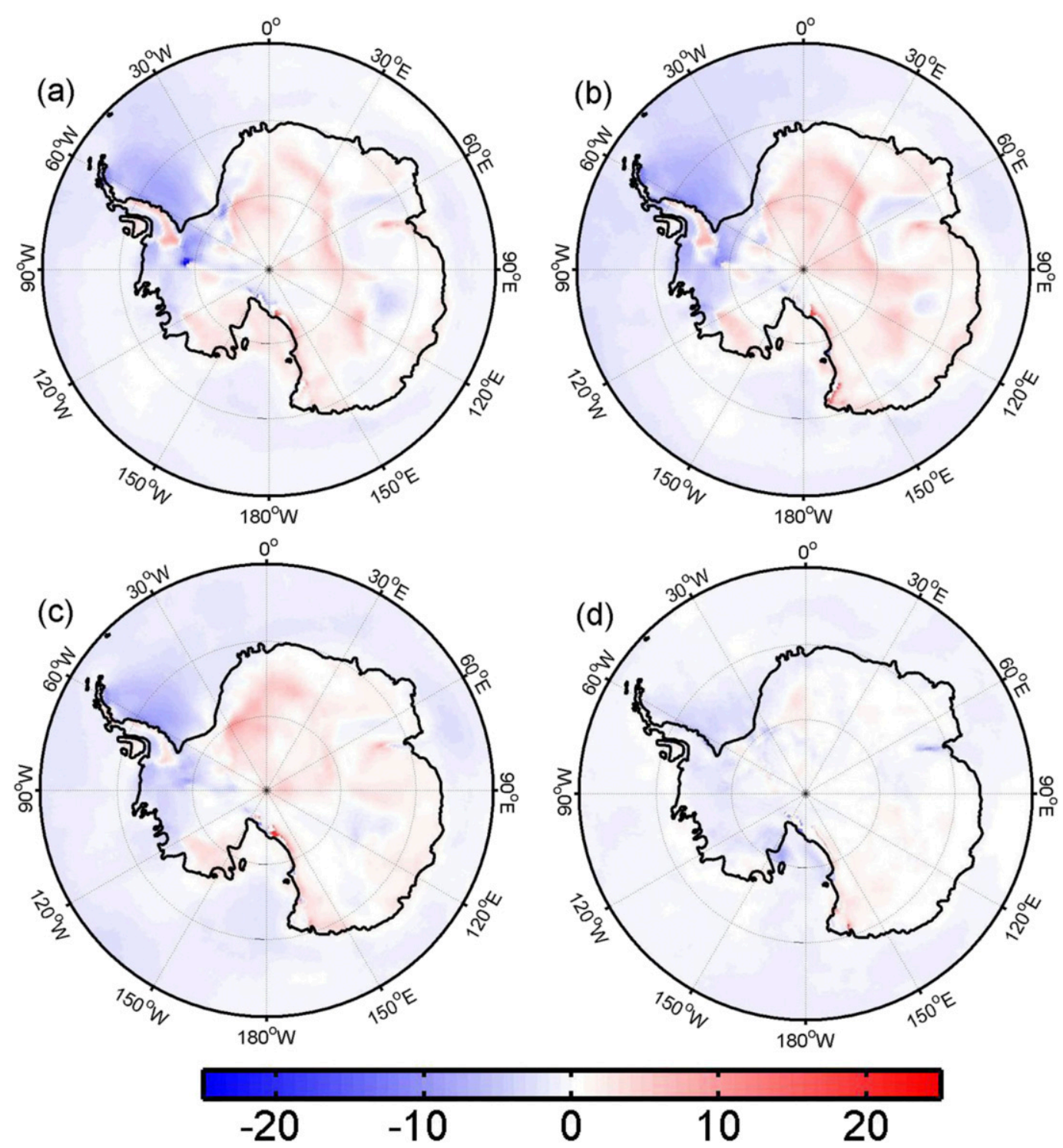

FIG. 7. As in Fig. 5, but for 500-hPa potential height ( $\times 100 \mathrm{gpm})$.

oceanic circulations on interannual time scale. We investigate the relationship between the interannual variability of SWE in Antarctica and the surrounding oceans and the southern annular mode (SAM), the leading mode of variability of Southern Hemisphere atmospheric circulations on intraseasonal and interannual time scales calculated as the first mode of empirical orthogonal function (EOF) analysis of monthly mean geopotential height anomalies at a fixed height level (Thompson and Wallace 2000). The second and third EOF modes correspond to the Pacific-South American (PSA) modes, which are related to SST in the tropical Pacific Ocean (Mo and Higgins 1998). Another known mode of climate variability on interannual time scale is El Niño/La Niña. Ciasto et al. (2015) noted that both the eastern and central Pacific El Niño/La Niña events are related to atmospheric circulation anomalies in the highlatitude Southern Hemisphere. Thus, we examine the possible teleconnection between the seasonal SWE occurrences in Antarctica and the El Niño/La Niña in eastern (the Niño-3 index) and central (the Niño-4 index) tropical Pacific Ocean. The regression maps of the seasonal number of SWE occurrences onto the seasonal mean Niño-3, Niño-4, and SAM indices are shown in Figs. 8-11 for each season, together with regression maps of seasonal mean MSLP anomalies onto these indices.

Statistically significant regression between the Niño-3 or Niño-4 indices and the MSLP anomalies appears over the southwestern Pacific Ocean. There are some differences between the regression to Niño-3 and to 

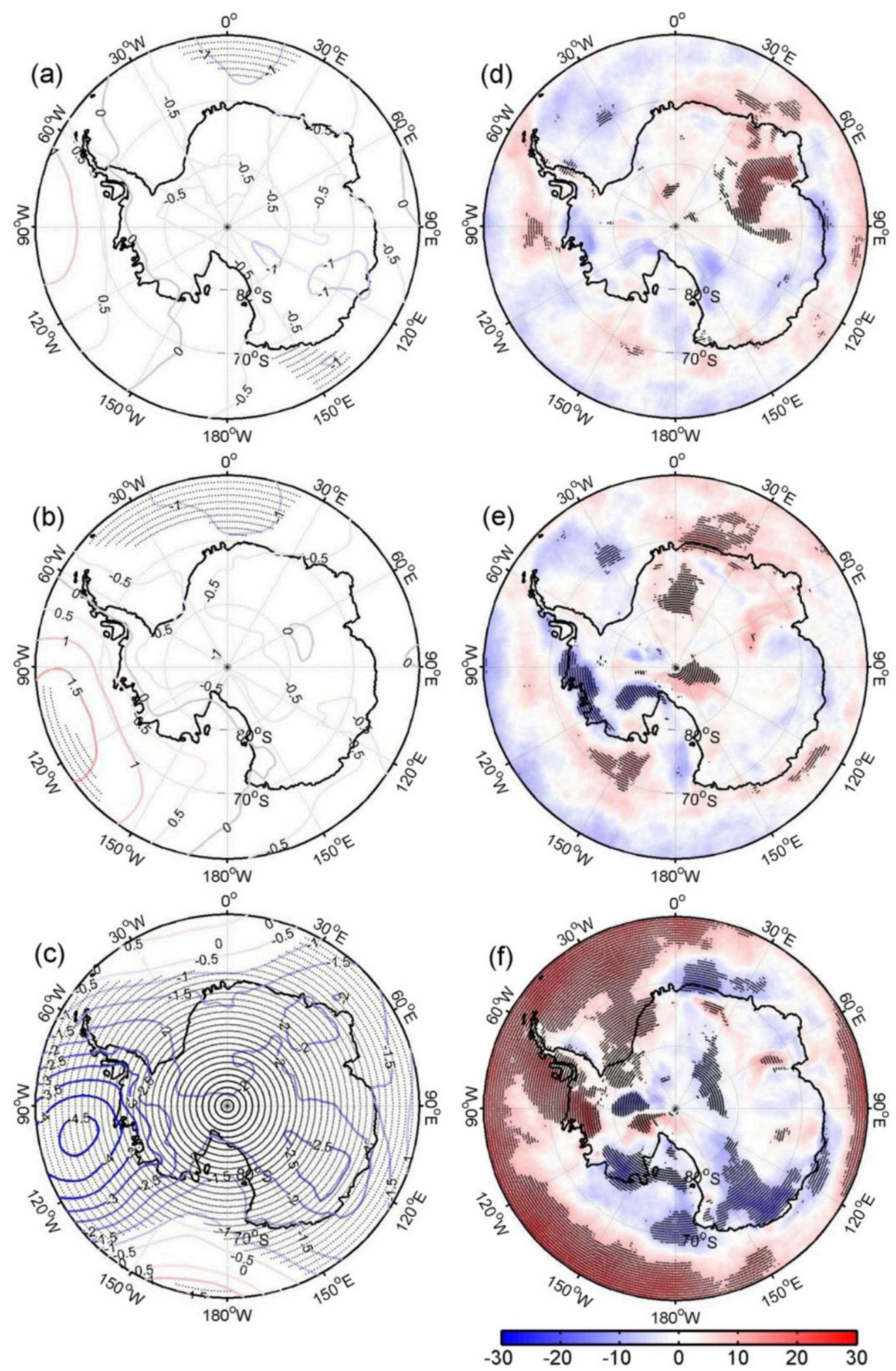

FIG. 8. Regression maps of (left) austral autumn MSLP (hPa) and (right) number of SWE occurrences into the (a),(d) Niño-3, (b),(e) Niño-4, and (c),(f) SAM indices. The dotted regions denote statistical significance at the above $95 \%$ confidence level. 

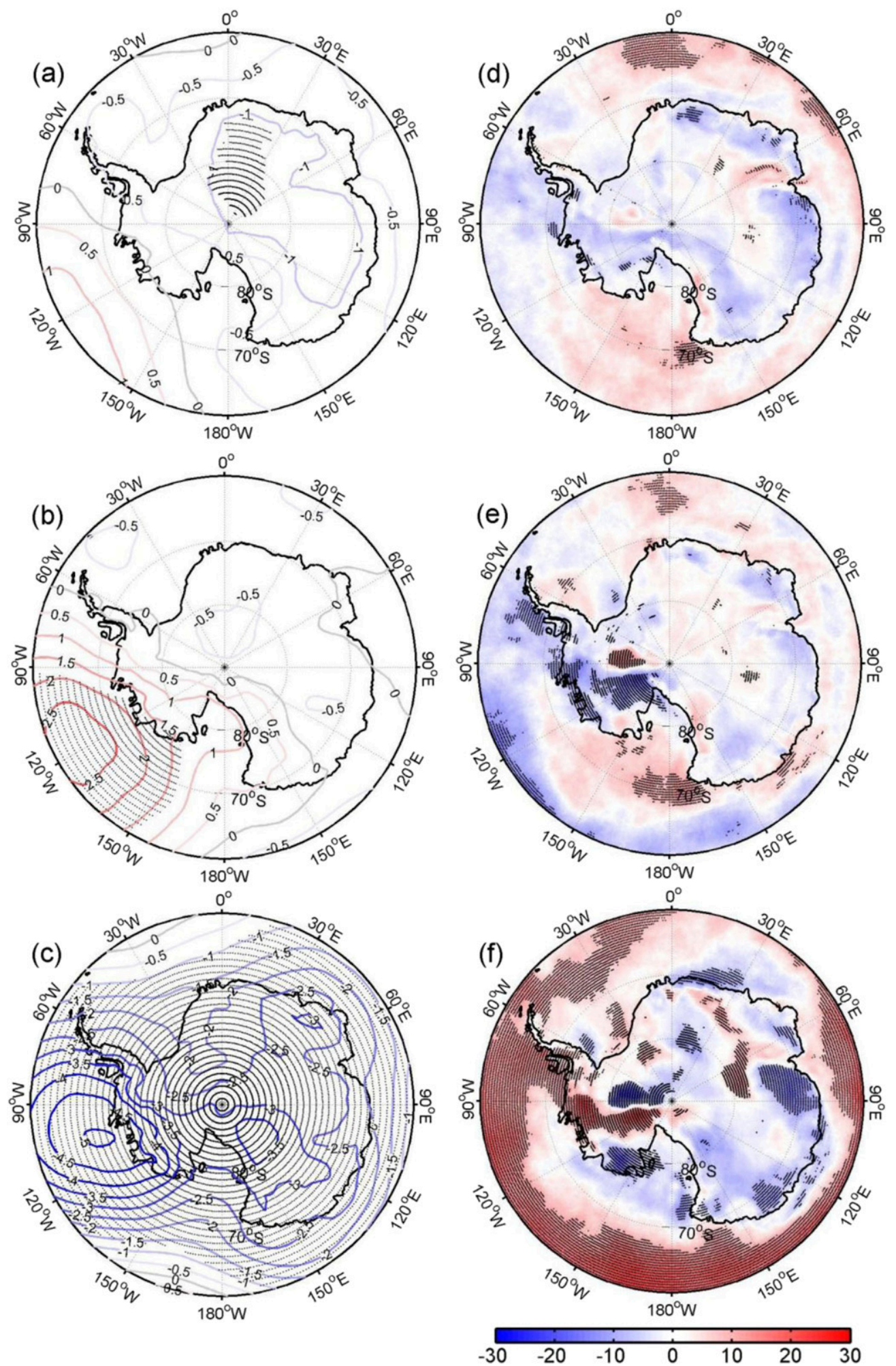

FIG. 9. As in Fig. 8, but for austral winter. 

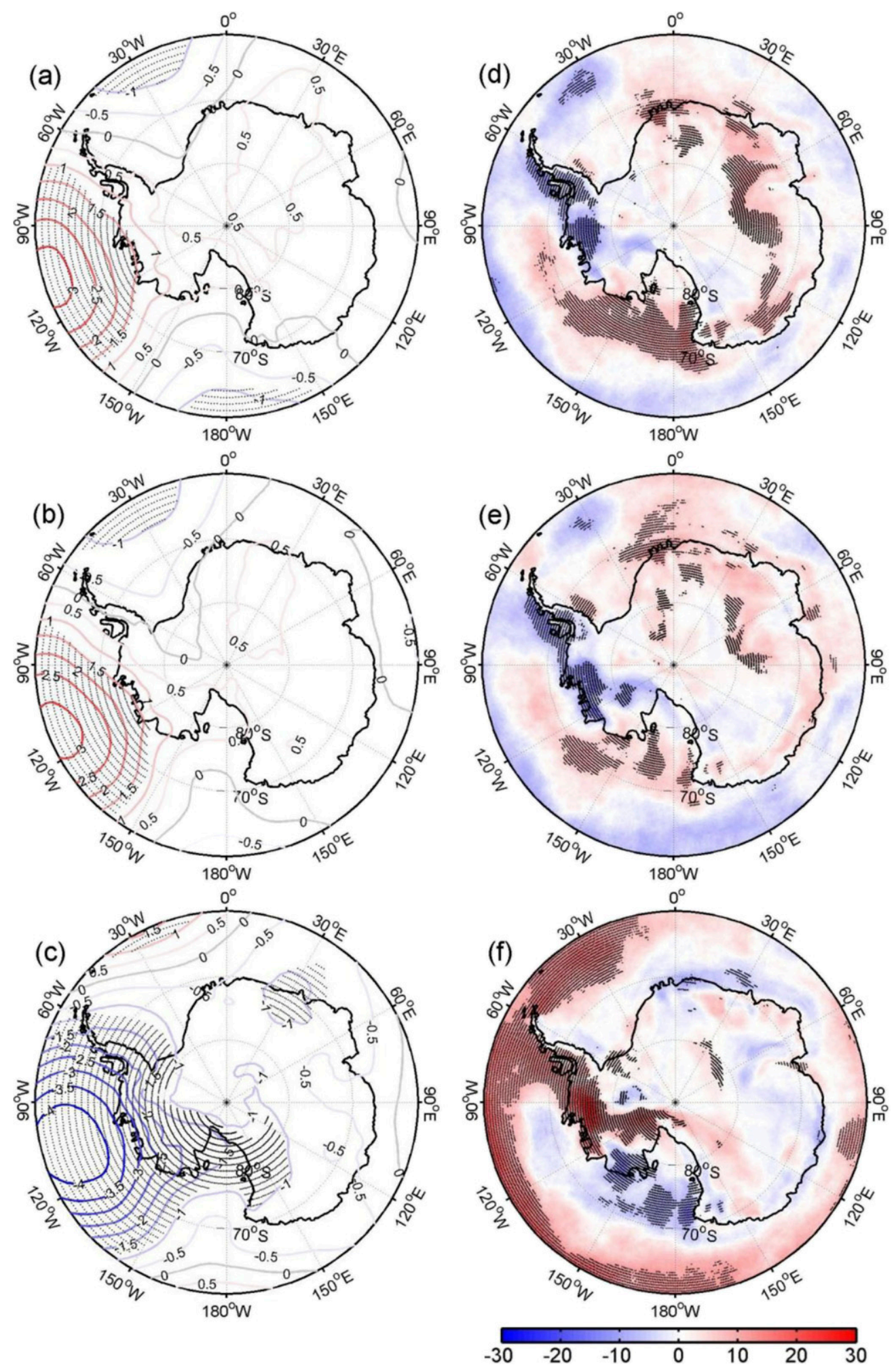

FIG. 10. As in Fig. 8, but for austral spring. 

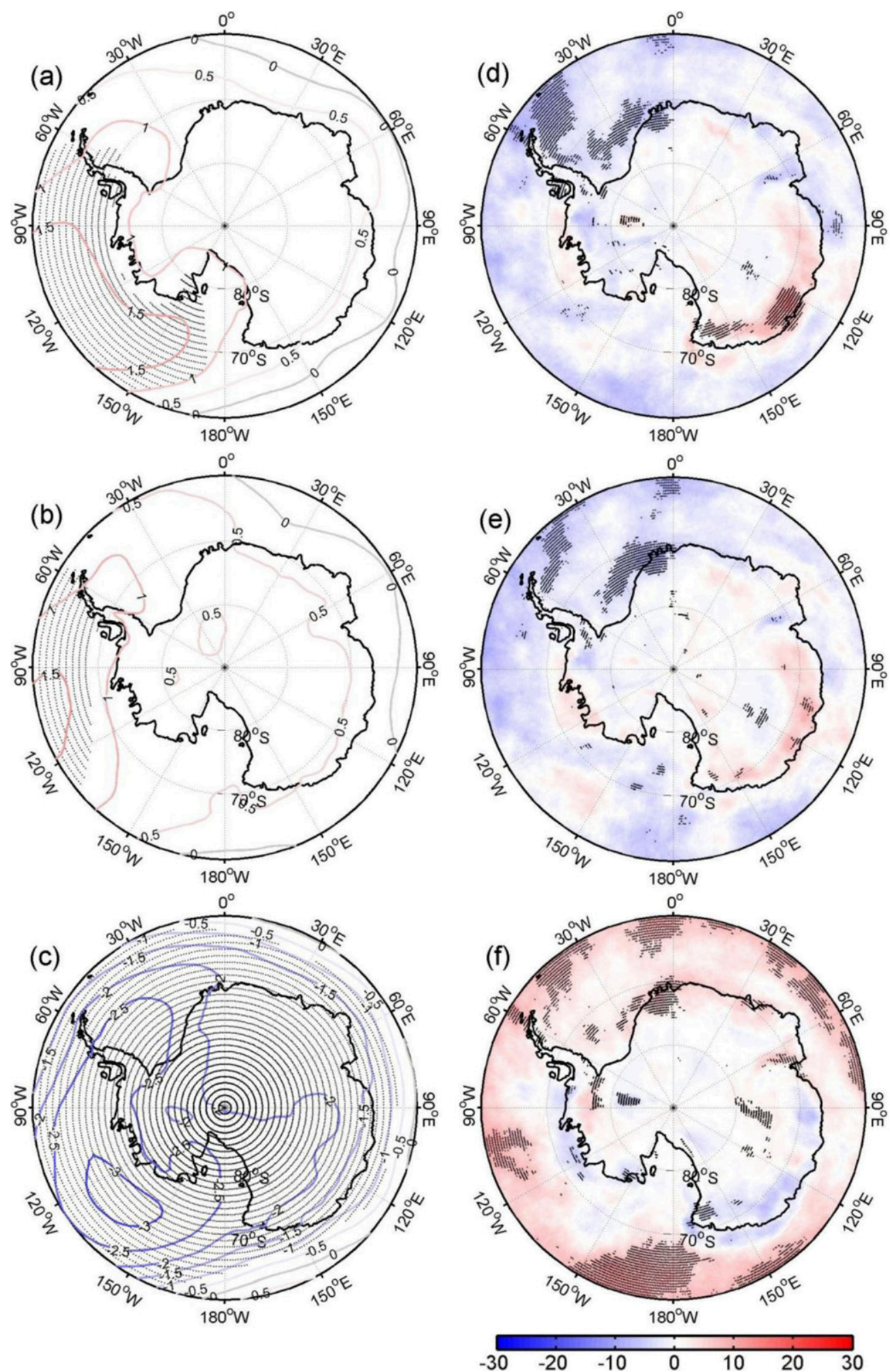

FIG. 11. As in Fig. 8, but for austral summer. 
Niño-4, with positive MSLP anomalies associated with Niño-3 appearing more westward than those associated with Niño-4. Statistically significant regression also occurs over the southern Atlantic Ocean, but only for austral spring and autumn (Figs. 10a,b). In austral autumn, an anomalous zonal pressure gradient over East Antarctica (longitude $60^{\circ} \mathrm{E}$ ) related to a positive Niño-3 (Fig. 8a) reinforces the climatological pressure gradient in the region and the increased pressure gradient is in agreement with positive SWEs anomalies in the region (Fig. 8d). The larger number of SWEs over the southern Indian Ocean (longitude $30^{\circ} \mathrm{E}$ ) seems to be related to a stronger meridional pressure gradient relative to climatological values (Fig. 3a). In contrast to Niño-3, Niño4 results in significant negative MSLP anomalies over the southern Atlantic Ocean and Dronning Maud Land (Fig. 8b), strengthening the meridional and zonal pressure gradient and favoring more SWEs in these regions (Fig. 8e). The reduced SWE occurrences over West Antarctica (Fig. 8e) are consistent with the reduced pressure gradient corresponding to the positive MSLP anomalies (Fig. 8b). The increase in the SWEs over the eastern Ross Sea appears to be related to the enhanced westerly winds induced by anomalous MSLP there.

In austral winter, positive anomalies of SWEs related to Niño-3 and -4 occur mainly over the southern Atlantic Ocean and the western Ross Sea (Figs. 9d,e), where the anomalous MSLP patterns result in stronger westerly and easterly winds (Figs. 9a,b), respectively. Niño-4 is also accompanied by significantly less SWEs over the southeastern Pacific Ocean and West Antarctica (Fig. 9e), where positive MSLP anomalies occur (Fig. 9b).

In austral spring, negative SWE anomalies associated with Niño-3 and -4 occur over the West Antarctica coast (Figs. 10d,e), where MSLP anomalies are significantly positive (Figs. 10a,b). Positive SWE anomalies can be seen over the Ross Sea and East Antarctica, where the MSLP anomaly pattern indicates an increase in pressure gradient between the ocean and the inland regions (Figs. 10d,e).

In austral summer, the SWE anomalies associated with Niño-3 and -4 are mostly negative except for a small patch over Wilkes and Oates Lands where significant positive anomalies are found (Figs. 11d,e). Significant negative SWE anomalies occur over the Weddell Sea, possibly resulting from the reduced westerly winds related to the positive MSLP anomalies in the region (Figs. 11a,b). Similar to the results of Chenoli et al. (2013), there appears to be no significant connection between El Niño and SWEs over the Ross Ice Shelf for all seasons, as the MSLP anomalies related to El Niño occur over the Bellingshausen and Amundsen Seas.

For all seasons, SAM corresponds to negative MSLP anomalies over most of study region with the smallest value over the Amundsen Sea (Figs. 8c, 9c, 10c, and 11c). The negative MSLP anomalies are favorable for increased westerly winds and more cyclones, which may result in more SWEs over the Southern Ocean (Figs. 8e, 9e, 10e, and 11e). The negative MSLP anomalies over the Amundsen Sea suggest a deepening of the Amundsen low (Figs. 8c, 9c, and 10c), which may contribute to the increased SWE occurrences over the Bellingshausen Sea and Ellsworth Land (Figs. 8e, 9e, and 10e). The anomalous ridge over the Ross Sea in austral spring, autumn, and winter weakens the meridional pressure gradient, reducing the chance for SWEs in the region. SAM is also related to less number of SWEs in austral winter and autumn over East Antarctica, such as in Princess Elizabeth and George V Lands.

\section{d. Trend}

Next, we examine trends in the seasonal number of SWEs in different regions of Antarctica and the surrounding oceans and explore the potential link to the trends in MSLP and surface temperature anomalies. For all seasons, there are considerable regional variations in the sign and magnitude of the trends, and overall more regions have statistically significant positive trends compared to those with significant negative trends (Fig. 12). Significant positive trends occur over the southern Indian Ocean, the Bellingshausen Sea, the Antarctic Peninsula, and parts of East Antarctica in austral autumn, in the region between $30^{\circ} \mathrm{W}$ and $90^{\circ} \mathrm{E}$ and the Ross Sea in winter, over East Antarctica and Amundsen Sea in spring, and everywhere except for the coastal regions of Amundsen Sea and the area near the Dumont d'Urville station in summer. Negative trends occur over the western Ross Sea, George V Land, and Edith Ronne Land in austral autumn, over Victoria Land in winter, over Victoria Land and the southwestern Pacific Ocean in spring, and over a small part of ocean near Oates Land and Amundsen Sea in summer.

The spatial patterns of trends in the seasonal number of SWEs closely match those of seasonal mean wind speed trends (Fig. 13), with spatial correlation coefficients of $0.90,0.87,0.88$, and 0.76 for austral autumn, winter, spring, and summer, respectively. The high spatial correlations for all seasons suggest a significant contribution to the changes of SWEs from the shift of the average value in the distribution of wind speeds (Kodra and Ganguly 2015).

A comparison of the spatial pattern of the SWE trends with the pattern of the MSLP anomaly trends for each season (Fig. 14) may help explain the regional differences in the SWE trends. The negative MSLP trends over the Bellingshausen and Amundsen Seas indicate a gradual deepening of the climatological Amundsen low (Fig. 14a), 

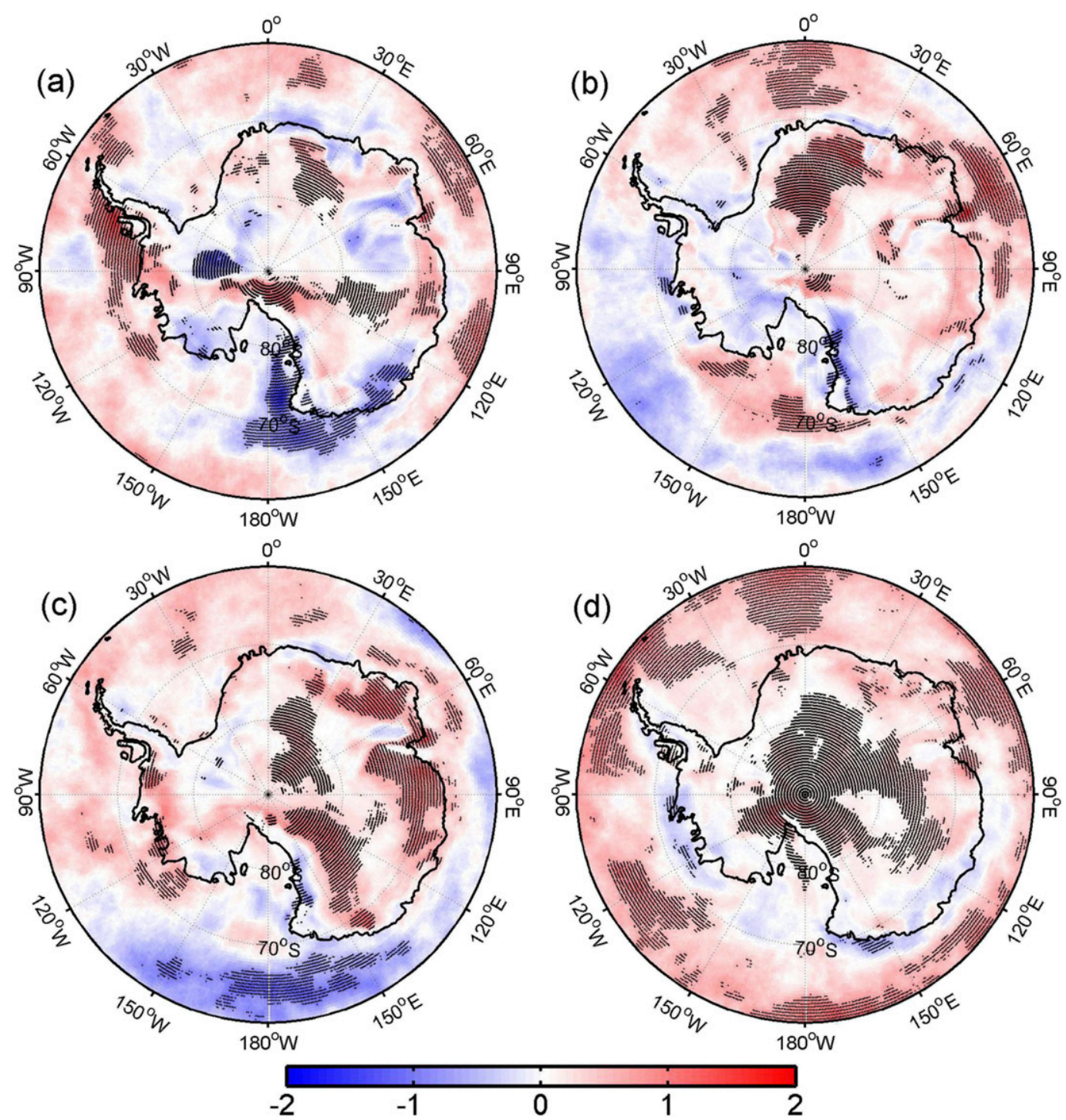

FIG. 12. Trends in the number of SWE $\left(\mathrm{yr}^{-1}\right)$ from 1979 to 2016 over the Antarctic continent and its surrounding seas for (a) austral autumn, (b) austral winter, (c) austral spring, and (d) austral summer. The dotted regions are statistically significant above the $95 \%$ confidence level.

which is consistent with the increasing trend in SWEs in the region (Fig. 12a). The positive MSLP trends between Edward VII Land and the Ross Sea contribute to the weakening of the climatological pressure gradient between them, supporting the downward trend in SWEs over the Ross Sea. The positive SWE trends over East Antarctica are associated with two relatively high MSLP centers inland that can strengthen the katabatic winds. The positive SWE anomalies over the southern Indian Ocean are linked with two low MSLP centers there.

In austral winter, the decreasing trends in SWEs over the coastal region of the Ross Sea and the positive SWE trends over Dronning Maud Land (Fig. 12b) correspond to the negative and positive MSLP trends in these regions, respectively (Fig. 14b). The positive SWE trends over the Southern Ocean (longitude $0^{\circ}$ and $60^{\circ} \mathrm{E}$ ) are consistent with an increase in the anomalous westerly winds associated with the negative MSLP trends there (Fig. 12b).

In austral spring, negative SWE trends over the southern Pacific Ocean (Fig. 12c) are related to the weakened westerly winds related to the negative MSLP trends there (Fig. 14c). In contrast, positive MSLP trends over East Antarctica strengthen climatological high pressure (Fig. 3c) and contribute to the positive SWE trends in the region.

In austral summer, negative MSLP trends occur over most of the study region (Fig. 14d), which, also observed by Yu et al. (2018), corresponds to a positive trend in the 

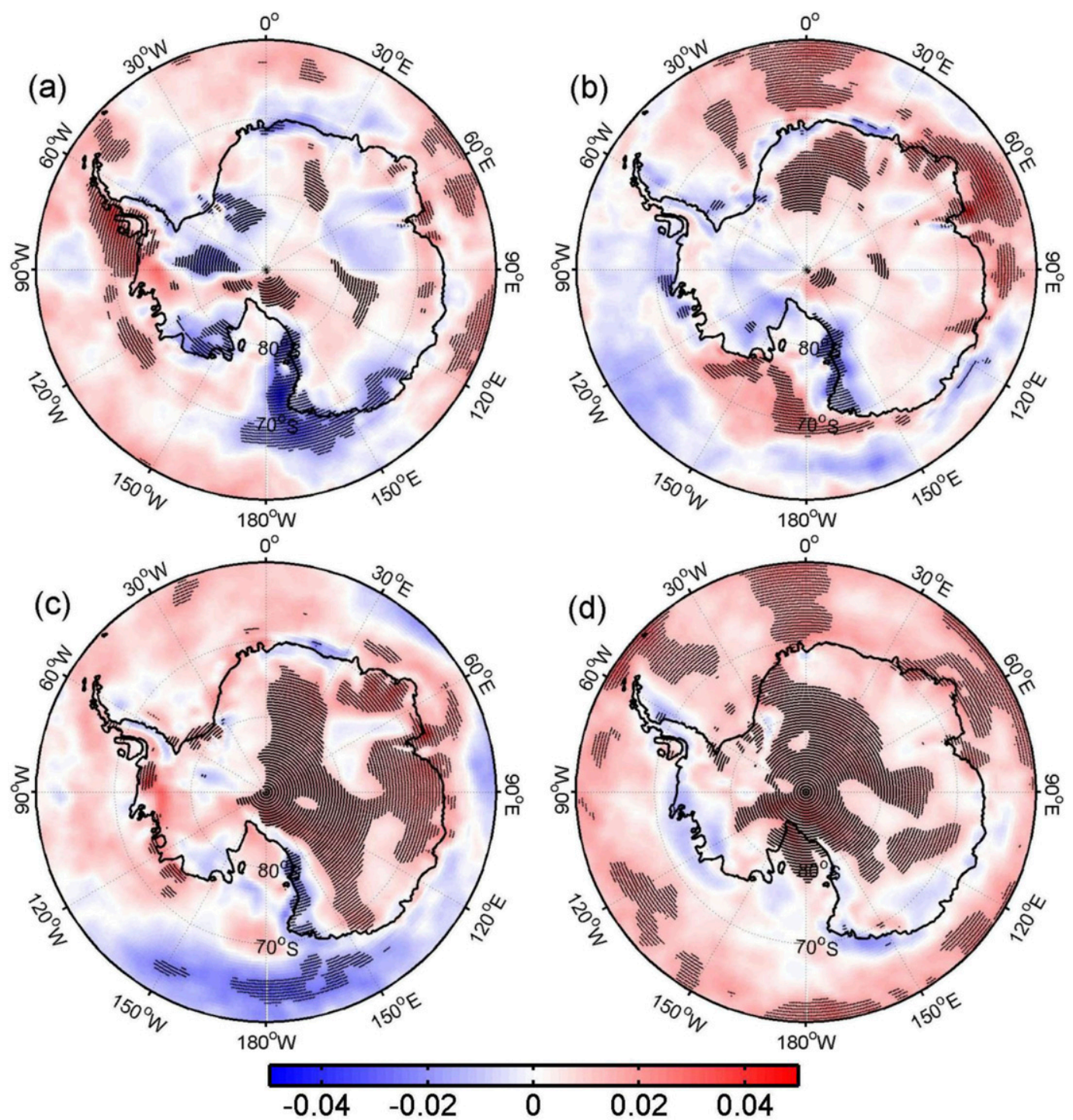

FIG. 13. Trends in seasonal mean wind speed anomalies $\left(\mathrm{m} \mathrm{s}^{-1} \mathrm{yr}^{-1}\right)$ from 1979 to 2017 over the Antarctic continent and its surrounding seas for (a) austral autumn, (b) austral winter, (c) austral spring, and (d) austral summer. The filled regions are statistically significant above the $95 \%$ confidence level.

summertime SAM index (Yu et al. 2018) that has been attributed to the common forcing of increasing greenhouse gas, changes in aerosol loading, and ozone depletion (Thompson and Solomon, 2002; Marshall et al. 2004; Arblaster and Meehl 2006; Gillett et al. 2013; Christidis and Stott 2015). The anomalous pressure gradients are in favor of stronger westerly winds and more SWEs over the Southern Ocean (Fig. 12d). The higher pressure over the South Pole relative to its vicinity (Fig. 14d) strengthens the climatological high pressure over East Antarctica (Fig. 3d), contributing to the positive SWE trends found in the region (Fig. 12d).

The composite analysis discussed earlier show that except for austral summer the occurrences of SWEs in regions of Antarctica are typically accompanied by a strong warming in the region (Fig. 4). There is, thus, a reason to believe that changes in the SWE occurrences are related, at least partially, to changes in the seasonal mean temperature. To explore this relationship, the correlation of the seasonal number of SWEs and seasonal mean surface air temperature are calculated for each season and the results are shown in Figs. 15a-d. In austral spring, autumn, and winter, more frequent SWEs are related to higher seasonal mean surface temperature in most regions except for George V Land, Mac. Robertson Land, and the southeastern Pacific Ocean where the opposite occurs. The relationship is insignificant for austral summer. 

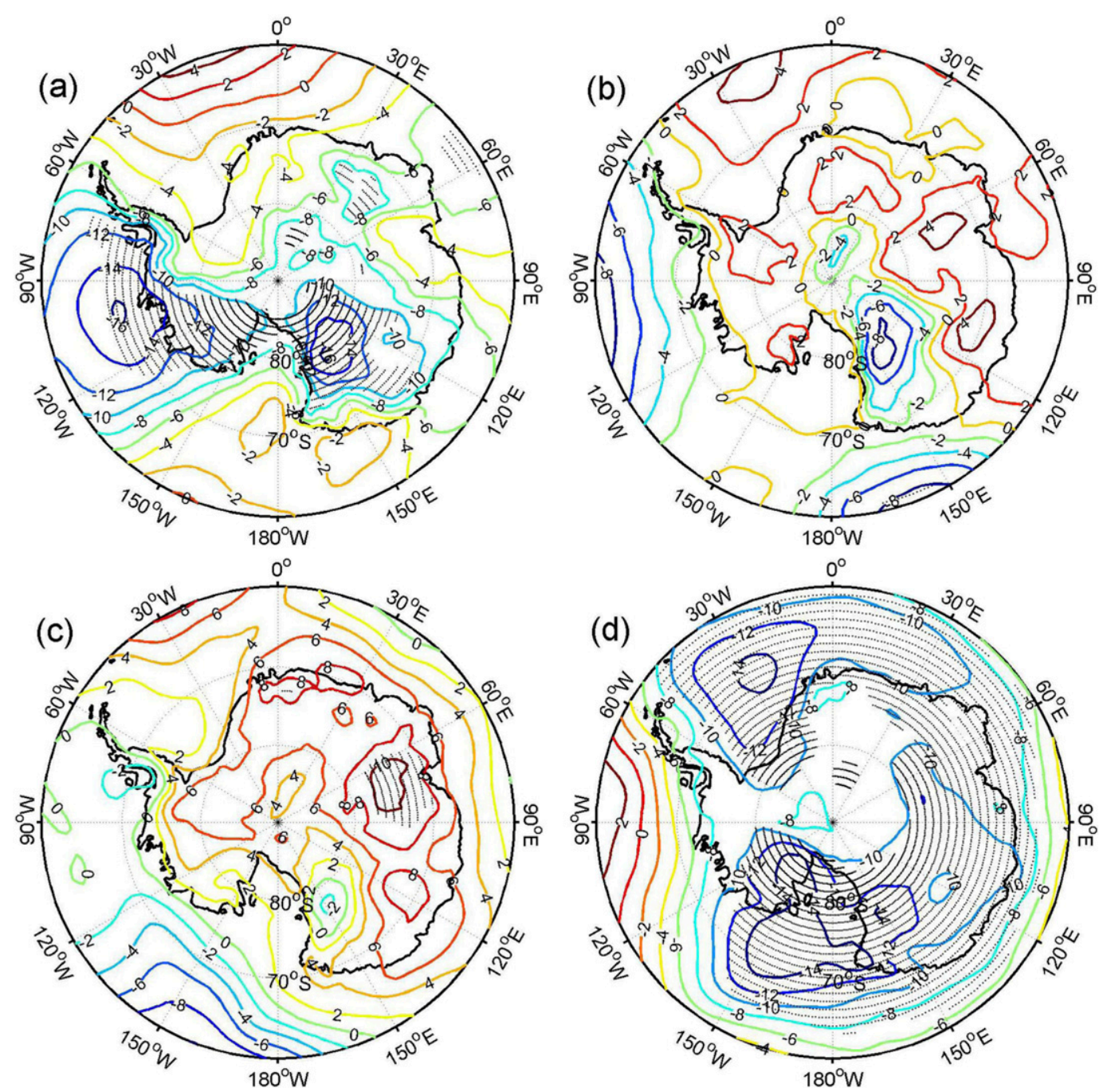

FIG. 14. Trends in seasonal MSLP $\left(\mathrm{Pa} \mathrm{yr}^{-1}\right)$ from 1979 to 2017 over the Antarctic continent and its surrounding seas for (a) austral autumn, (b) austral winter, (c) austral spring, and (d) austral summer. The filled regions are statistically significant above the $95 \%$ confidence level.

The trends in the number of SWEs can also be related to the trends in the seasonal mean surface temperature (Figs. 15e,h). In austral autumn, the warming over the Bellingshausen Sea (Fig. 15e) and the cooling over the southern Indian Ocean (longitude $90^{\circ}-120^{\circ} \mathrm{E}$ ) correspond to positive SWE trends in these regions (Fig. 12a). In contrast, the trends in both autumn surface temperature and SWEs are negative over the western Ross Sea. In austral winter, negative (positive) SWE trends are accompanied by negative (positive) trends in surface temperature over the southwestern Pacific Ocean (the Ross Sea and the southern Indian Ocean). In austral spring, positive SWE trends correspond to warming trends over the interiors of East Antarctica and the Amundsen Sea, and the opposite occurs over the southwestern Pacific Ocean. In austral summer, the upward
SWE trends over southwestern Pacific Ocean are accompanied by cooling trends there.

\section{Summary and discussion}

The four times daily $10-\mathrm{m}$ wind speed data for the 1979-2017 period from ERA-Interim are utilized to investigate the occurrences of SWEs over Antarctica and its surrounding oceans. Specifically, the analyses show regional and seasonal variations of the mean number of SWE occurrences, interannual variability and trend over the 38-yr study period. The analyses also explore the potential link of the SWE interannual variability to some of the well-known climate variability modes at the interannual time scale, such as Niño-3, Niño-4, and SAM, and the relationship of the SWE trends and the 

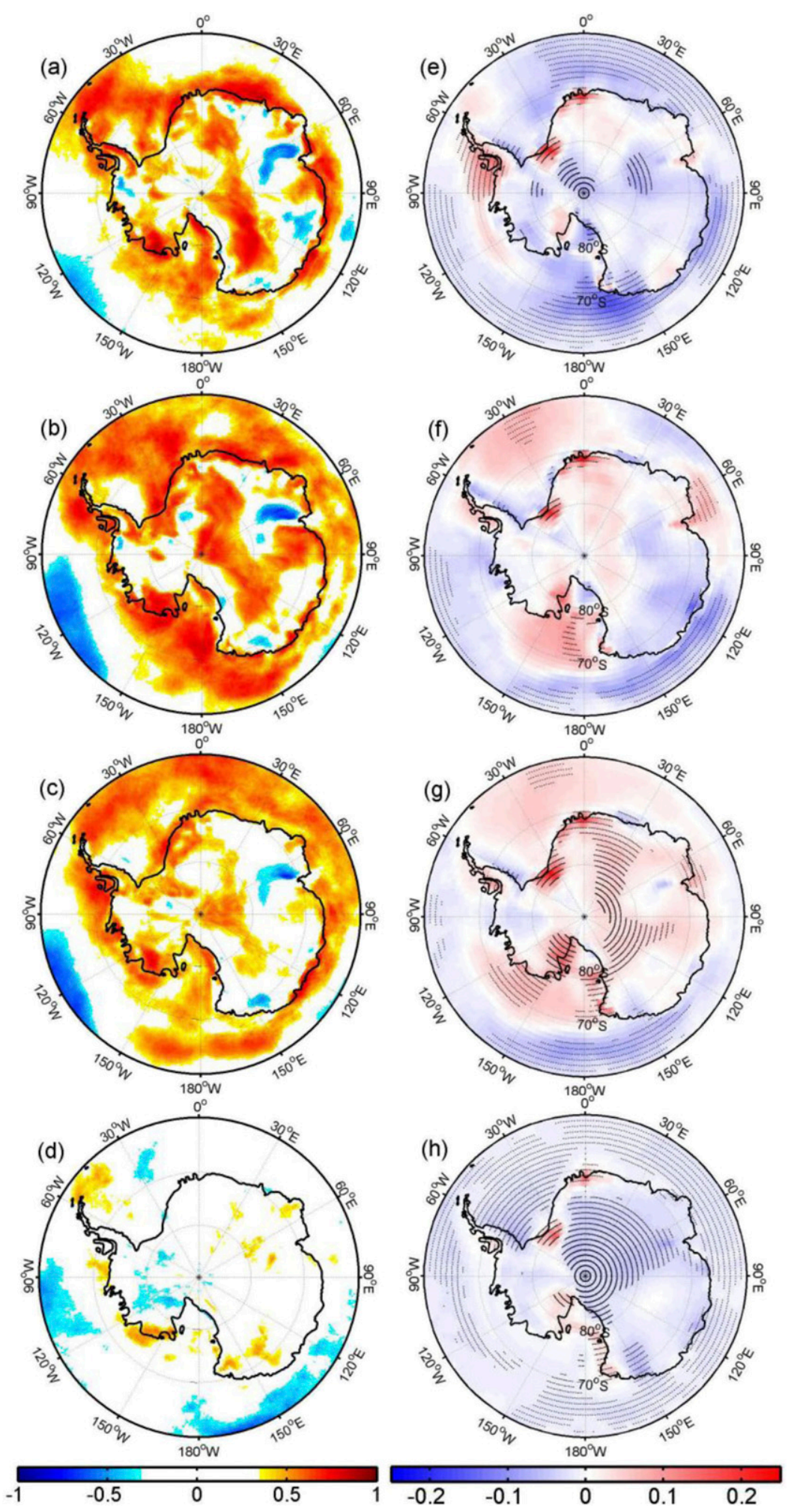

FIG. 15. (a)-(d) Correlations between the seasonal number of SWEs and the seasonal mean surface air temperature and (e)-(h) the trends in seasonal mean surface air temperature $\left({ }^{\circ} \mathrm{C} \mathrm{yr}^{-1}\right)$ for (a),(e) austral autumn, (b), (f) austral winter, (c), (g) austral spring, and (d),(h) austral summer. Only statistically significant correlation coefficients above 95\% confidence level are shown in (a)-(d) and the dotted regions in (e)-(h) denote statistical significance the above $95 \%$ confidence level. 
trends in atmospheric variables such as surface air temperature and MSLP.

Most SWEs occur over the coastal region of East Antarctica and the occurrences exhibit strong seasonality. There is a $50 \%$ increase in the average number of SWE occurrences across the domain from austral summer to autumn, another $11 \%$ increase from autumn to winter, and everywhere the seasonal variation is consistent with changes in seasonal mean wind speed. Over the ice shelves and coastal regions, SWE occurrences are usually accompanied by negative MSLP and positive surface temperature anomalies related largely to mesoscale cyclone activities. Over the interiors of East Antarctica, positive SWE anomalies correspond to positive 500-hPa geopotential height and surface air temperature anomalies related to the penetration of anticyclones into the inland regions. Despite the strong correlation between positive temperature anomalies and SWEs, it is possible to have negative temperature anomalies accompanying SWEs (Turner et al. 2009). Whether there is positive or negative temperature anomaly during a SWE at a grid point depends on the position of cyclones relative to the location of the grid point.

The SWE occurrences also display a strong interannual variability that can be explained partially by the large-scale climate variability modes on interannual time scale, namely Niño-3, Niño-4, and SAM. The spatial regression patterns of the SWE anomalies onto the Niño-3 and -4 indices show large seasonal differences that appear to be related to seasonal influences of Niño3 and -4 on MSLP over different Antarctic regions especially the southeastern Pacific Ocean. During the positive phase of SAM, deeper low pressure over the southern high latitudes and the associated stronger westerlies appear to contribute to the increase in SWEs over the Southern Ocean. Meanwhile the lower pressure over the Bellingshausen and Amundsen Sea also is favorable for more SWEs over the Bellingshausen Sea and West Antarctica. The strengths of the relationship between SAM and SWEs vary with season. Chenoli et al. (2013) noted an unstable positive correlation between the autumn SAM index and the number of autumn SWEs for the 1979-2005 period, with significant correlation of 0.6 existing only for the period 1990-2000. A calculation of correlations between the SAM index and the number of SWEs here for each season for the 19792016 period shows regionally significant correlations.

Trends in SWE occurrences vary considerably across the land and the oceans and between seasons, but for all seasons, statistically significant positive trends expand to cover more regions than those covered by significant negative trends. The direction and magnitude of trends are consistent with previous studies at those locations where trends were documented using station observations (e.g., Turner et al. 2009; Chenoli et al. 2013). The trends in the seasonal number of SWEs, which are consistent with the trends in seasonal mean wind speed, can be largely explained by the changes in the seasonal MSLP anomaly patterns. Except for austral summer, the SWE trend and its seasonal variability appear to be closely associated with the trend and seasonality of surface temperature. Such relationship does not exist in austral summer. This result suggests that trends in Antarctic surface temperature may be explained from the perspective of SWE change, although previous studies have noted the important role of synoptic processes in the interannual and interdecadal variability and trend in the Antarctic surface temperature (Palmer 1993, 1999; Lee et al. 2011; Lee and Feldstein 2013).

The discussion above on the trends in Antarctic surface temperature is from the perspective of synoptic-scale forcing. Another large-scale forcing for the changes in the surface temperature over Antarctica is the changes in stratospheric ozone concentration over Antarctica that increases the circumpolar westerlies (Thompson and Solomon, 2002). In addition, Steig et al. (2009) found that SST, sea ice, and radiative forcing play an important role in the changes of Antarctic surface temperature. They also noted that a zonal wave-3 pattern is related to temperature trends, which is also shown in the current analysis. Ding et al. (2011) related winter warming in West Antarctica to the central tropical Pacific warming. The results here help highlight the role of synoptic processes in linking the variations in seasonal Antarctic surface temperature and atmospheric circulations caused by aforementioned factors. The importance of synoptic processes in the interannual and interdecadal variability and trend of a certain atmospheric variable has been noted in previous studies (Palmer 1993, 1999; Lee et al. 2011; Lee and Feldstein 2013).

Although the horizontal resolution of $80 \mathrm{~km}$ in the ERA-Interim wind data is relatively high compared to earlier reanalysis products, the smoothed terrain in the gridded data can influence the strength of SWE (Steinhoff et al. 2009), especially over the coastal region of East Antarctica where SWEs are most frequent and dominated by katabatic forcing related to the sharp coastal slopes. The grid averaged winds can also underestimate actual winds in summertime coastal regions as a result of underestimated sea and land breezes, which can influence the strength and number of SWEs. Finally, it is worth noting that in this study a SWE is considered to have occurred if the wind speed criterion is satisfied at any given time when the data are available. Given the 6-hourly temporal resolution of the ERAInterim wind data, this approach tends to overestimate 
SWE occurrences since these events usually persist over $6 \mathrm{~h}$. Although this bias has little effect on the trend and variability analyzed here, future studies should consider not only high winds, but also the duration of high winds.

Despite above-mentioned limitations, our results about SWEs can offer some suggestions for wind resource exploration. Knowledge about the seasonal and interannual variability and trends of SWEs can be useful for effective seasonal and long-term planning of infrastructure and personnel at the Antarctic stations.

Model simulations from phase 5 of the Coupled Model Intercomparison Project (CMIP5) based on the representative concentration pathway 8.5 (RCP8.5) suggested a significant positive trend in SAM over this century (Zheng et al. 2013), which, according to the relationship between SAM and SWE established in this analysis, will likely to result in a future increase in SWE events in the Southern Ocean and parts of West Antarctica. More frequent El Niño episodes projected for the future will likely produce more westerly wind events over the Amundsen Sea, thus leading to the melt of the ice shelf there (Bracegirdle et al. 2014).

Acknowledgments. We thank the European Centre for Medium-Range Weather Forecasts (ECMWF) for the ERA-Interim data. This study is financially supported by the National Key R\&D Program of China (2018YFA0605701) and Shanghai Pujiang Program (17PJ1409800).

\section{REFERENCES}

Adams, N., 2005: Identifying the characteristics of strong southerly wind events at Casey station in East Antarctica using a numerical weather prediction system. Mon. Wea. Rev., 133, 3548-3561, https://doi.org/10.1175/MWR3050.1.

Arblaster, J. M., and G. A. Meehl, 2006: Contributions of external forcings to southern annular mode trends. J. Climate, 19, 28962905, https://doi.org/10.1175/JCLI3774.1.

Birnbaum, G., R. Brauner, and H. Ries, 2006: Synoptic situations causing high precipitation rates on the Antarctic plateau: Observations from Kohnen Station, Dronning Maud Land. Antarct. Sci., 18, 279-288, https://doi.org/10.1017/S0954102006000320.

Bracegirdle, T. J., J. Turner, J. S. Hosking, and T. Phillips, 2014: Sources of uncertainty in projections of twenty-first century westerly wind changes over the Amundsen Sea, West Antarctica, in CMIP5 climate models. Climate Dyn., 43, 20932104, https://doi.org/10.1007/s00382-013-2032-1.

Chenoli, S. N., J. Turner, and A. A. Samah, 2013: A climatology of strong wind events at McMurdo station, Antarctica. Int. J. Climatol., 33, 2667-2681, https://doi.org/10.1002/joc.3617.

,-- , and — 2015: A strong wind event on the Ross Ice Shelf, Antarctica: A case study of scale interactions. Mon. Wea. Rev., 143, 4163-4180, https://doi.org/10.1175/MWR-D15-0002.1.

Christidis, N., and P. A. Stott, 2015: Changes in the geophysical height at $500 \mathrm{hPa}$ under the influence of external climatic forcings. Geophys. Res. Lett., 42, 10 798-10 806, https://doi.org/ 10.1002/2015GL066669.

Ciasto, L. M., G. R. Simpkins, and M. H. England, 2015: Teleconnections between tropical Pacific SST anomalies and extratropical Southern Hemisphere climate. J. Climate, 28, 56-65, https://doi.org/10.1175/JCLI-D-14-00438.1.

Deb, P., A. Orr, D. H. Bromwich, J. P. Nicolas, J. Turner, and J. S. Hosking, 2018: Summer drivers of atmospheric variability affecting ice shelf thinning in the Amundsen Sea Embayment, West Antarctica. Geophys. Res. Lett., 45, 4124-4133, https:// doi.org/10.1029/2018GL077092.

Dee, D. P., and Coauthors, 2011: The ERA-Interim reanalysis: Configuration and performance of the data assimilation system. Quart. J. Roy. Meteor. Soc., 137, 553-597, https://doi.org/ 10.1002/qj.828.

Déry, S. J., and M. K. Yau, 2002: Large-scale mass balance effects of blowing snow and surface sublimation. J. Geophys. Res., 107, 4679, https://doi.org/10.1029/2001JD001251.

Ding, Q., E. J. Steig, D. S. Battisti, and M. Küttel, 2011: Winter warming in West Antarctica caused by central tropical Pacific warming. Nat. Geosci., 4, 398-403, https://doi.org/10.1038/ ngeo1129.

Gillett, N. P., J. C. Fyfe, and D. E. Parker, 2013: Attribution of observed sea level pressure trends to greenhouse gas, aerosol, and ozone changes. Geophys. Res. Lett., 40, 2302-2306, https:// doi.org/10.1002/grl.50500.

Holmes, R. E., C. R. Stearns, G. A. Weidner, and L. M. Keller, 2000: Utilization of automatic weather station data for forecasting high wind speeds at Pegasus Runway, Antarctica. Wea. Forecasting, 15, 137-151, https://doi.org/10.1175/1520-0434(2000) 015<0137:UOAWSD > 2.0.CO;2.

King, J. C., and J. Turner, 1997: Antarctic Meteorology and Climatology. Cambridge University Press, 409 pp.

Kodra, E., and A. R. Ganguly, 2015: Asymmetry of projected increases in extreme temperature distributions. Sci. Rep., 4, 5884, https://doi.org/10.1038/srep05884.

Kottmeier, C., and R. Hartig, 1990: Winter observations of the atmosphere over Antarctic sea ice. J. Geophys. Res., 95, 16551-16560, https://doi.org/10.1029/JD095iD10p16551.

Lee, S., and S. B. Feldstein, 2013: Detecting ozone- and greenhouse gas-driven wind trends with observational data. Science, $\mathbf{3 3 9}$, 563-567, https://doi.org/10.1126/science.1225154.

- T. Gong, N. C. Johnson, S. B. Feldstein, and D. Pollard, 2011: On the possible link between tropical convection and the Northern Hemisphere Arctic surface air temperature change between 1958 and 2001. J. Climate, 24, 4350-4367, https:// doi.org/10.1175/2011JCLI4003.1.

Le Quéré, C. L., and Coauthors, 2007: Saturation of the Southern Ocean $\mathrm{CO}_{2}$ sink due to recent climate change. Science, 316, 1735-1738, https://doi.org/10.1126/science.1136188.

Marshall, J., P. A. Stott, J. Turner, W. M. Connolley, J. C. King, and T. A. Lachlan-Cope, 2004: Causes of exceptional atmospheric circulation changes in the Southern Hemisphere. Geophys. Res. Lett., 31, L14205, https://doi.org/10.1029/2004GL019952.

Mo, K. C., and R. W. Higgins, 1998: The Pacific-South American modes and tropical convection during the Southern Hemisphere winter. Mon. Wea. Rev., 126, 1581-1596, https://doi.org/ 10.1175/1520-0493(1998)126<1581:TPSAMA > 2.0.CO;2.

Monaghan, A. J., D. H. Bromwich, J. G. Powers, and K. W. Manning, 2005: The climate of the McMurdo, Antarctica, region as represented by one year of forecasts from the Antarctic Mesoscale Prediction System. J. Climate, 18, 1174-1189, https://doi.org/10.1175/JCLI3336.1. 
Murphy, B. F., and I. Simmonds, 1993: An analysis of strong wind events simulated in a GCM near Casey in the Antarctic. Mon. Wea. Rev., 121, 522-534, https://doi.org/10.1175/15200493(1993)121<0522:AAOSWE > 2.0.CO;2.

Nigro, M. A., J. J. Cassano, M. A. Lazzara, and L. M. Keller, 2012: Case study of a barrier wind corner jet off the coast of the Prine Olav Mountains, Antarctica. Mon. Wea. Rev., 140, 2044 2063, https://doi.org/10.1175/MWR-D-11-00261.1.

O'Connor, W. E., D. H. Bromwich, and J. F. Carrasco, 1994: Cyclonically forced barrier winds along the Transantarctic Mountains near Ross Island. Mon. Wea. Rev., 122, 137-150, https://doi.org/ 10.1175/1520-0493(1994)122<0137:CFBWAT >2.0.CO;2.

Orr, A., T. Phillips, S. Webster, A. Elvidge, M. Weeks, S. Hosking, and J. Turner, 2014: Met Office Unified Model high-resolution simulations of a strong wind events in Antarctica. Quart. J. Roy. Meteor. Soc., 140, 2287-2297, https://doi.org/10.1002/qj.2296.

Palmer, T. N., 1993: A nonlinear dynamical perspective on climate change. Weather, 48, 314-326, https://doi.org/10.1002/j.14778696.1993.tb05802.x.

_- 1999: A nonlinear dynamical perspective on climate prediction. J. Climate, 12, 575-591, https://doi.org/10.1175/15200442(1999)012<0575:ANDPOC $>2.0 . C O ; 2$.

Parish, T. R., and J. J. Cassano, 2001: Forcing of the wintertime Antarctic boundary layer winds from the NCEP-NCAR global reanalysis. J. Appl. Meteor., 40, 810-821, https://doi.org/ 10.1175/1520-0450(2001)040<0810:FOTWAB $>2.0$.CO;2.

$\longrightarrow$, and _ 2003: The role of katabatic winds on the Antarctic surface wind regime. Mon. Wea. Rev., 131,317-333, https://doi.org/ 10.1175/1520-0493(2003)131<0317:TROKWO >2.0.CO;2.

Powers, J. G., A. J. Monaghan, A. M. Cayette, D. H. Bromwich, Y. H. Kuo, and K. W. Manning, 2003: Real-time mesoscale modeling over Antarctica: The Antarctic Mesoscale Prediction System. Bull. Amer. Meteor. Soc., 84, 1533-1545, https://doi.org/10.1175/BAMS-84-11-1533.

Rabier, F., J.-N. Thépaut, and P. Courtier, 1998: Extended assimilation and forecast experiments with a four-dimensional variational assimilation system. Quart. J. Roy. Meteor. Soc., 124, 1861-1887, https://doi.org/10.1002/qj.49712455005.

— H. Järvinen, E. Klinker, J.-F. Mahfouf, and A. J. Simmons, 2000: The ECMWF operational implementation of fourdimensional variational assimilation. I: Experimental results with simplified physics. Quart. J. Roy. Meteor. Soc., 126, 11431170, https://doi.org/10.1256/smsqj.56414.

Rodrigo, J. S., J.-M. Buchlin, J. van Beeck, J. T. M. Lenaerts, and M. R. van den Broeke, 2013: Evaluation of the Antarctic surface wind climate from ERA reanalyses and RACMO2/ANT simulations based on automatic weather stations. Climate Dyn., 40 , 353-376, https://doi.org/10.1007/s00382-012-1396-y.

Speirs, J. C., D. F. Steinhoff, H. A. McGowan, D. H. Bromwich, and A. J. Monaghan, 2010: Foehn winds in the McMurdo dry valleys, Antarctica: The origin of extreme warming events. J. Climate, 23, 3577-3598, https://doi.org/10.1175/2010JCLI3382.1.

Steig, E. J., D. P. Schneider, S. D. Rutherford, M. E. Mann, J. C. Comiso, and D. T. Shindell, 2009: Warming of the Antarctic icesheet surface since the 1957 International Geophysical Year. Nature, 457, 459-462, https://doi.org/10.1038/nature07669.
Steinhoff, D. F., D. H. Bromwich, M. Lambertson, S. L. Knuth, and M. A. Lazzara, 2008: A dynamical investigation of the May 2004 McMurdo Antarctica severe wind event using AMIPS. Mon. Wea. Rev., 136, 7-26, https://doi.org/10.1175/ 2007MWR1999.1.

— S. Chaudhuri, and D. H. Bromwich, 2009: A case study of a Ross Ice Shelf air stream event: A new perspective. Mon. Wea. Rev., 137, 4030-4046, https://doi.org/10.1175/2009MWR2880.1.

Thompson, D. W. J., and J. Wallace, 2000: Annular modes in the extratropical circulation. Part I: Month-to-month variability. J. Climate, 13, 1000-1016, https://doi.org/10.1175/1520-0442(2000) 013<1000:AMITEC>2.0.CO;2.

— Hemisphere climate change. Science, 296, 895-899, https:// doi.org/10.1126/science.1069270.

Tomikawa, Y., and Coauthors, 2015: Vertical wind disturbances during a strong wind event observed by the PANSY radar at Syowa station, Antarctica. Mon. Wea. Rev., 143, 1804-1821, https://doi.org/10.1175/MWR-D-14-00289.1.

Turner, J., T. A. Lachlan-Cope, G. J. Marshall, S. Pendlebury, and N. Adams, 2001: An extreme wind event at Casey Station, Antarctica. J. Geophys. Res., 106, 7291-7311, https://doi.org/ 10.1029/2000JD900544.

_ S. N. Chenoli, A. abu Samah, G. Marshall, T. Phillips, and A. Orr, 2009: Strong wind events in the Antarctic. J. Geophys. Res., 114, D18103, https://doi.org/10.1029/2008JD011642.

Uppala, S. M., and Coauthors, 2005: The ERA-40 Reanalysis. Quart. J. Roy. Meteor. Soc., 131, 2961-3012, https://doi.org/ 10.1256/qj.04.176.

van As, D., M. R. van den Broeke, and M. Helsen, 2007: Strongwind events and their impact on the near-surface climate at Kohnen Station on the Antarctic Plateau. Antarct. Sci., 19, 507-519, https://doi.org/10.1017/S095410200700065X.

van den Broeke, M. R., and N. P. M. van Lipzig, 2003: Factors controlling the near-surface wind field in Antarctica. Mon. Wea. Rev., 131, 733-743, https://doi.org/10.1175/1520-0493(2003) $131<0733$ :FCTNSW>2.0.CO;2.

van Lipzig, N. P., M. E. van Meijgaard, and J. Oerlemans, 2002: The spatial and temporal variability of the surface mass balance in Antarctica: Results from a regional atmospheric climate model. Int. J. Climatol., 22, 1197-1217, https://doi.org/10.1002/ joc. 798 .

Wilks, D. S., 2011: Statistical Methods in the Atmospheric Sciences. 3rd ed. Elsevier, 676 pp.

Yu, L., S. Zhong, W. E. Heilman, and X. Bian, 2017: A comparison of the effects of El Niño and El Niño Modoki on subdaily extreme precipitation occurrences across the contiguous United States. J. Geophys. Res., 122, 7401-7415, https:// doi.org/10.1002/2017JD026683.

,-- M. Zhou, B. Sun, and D. H. Lenschow, 2018: Antarctic summer sea ice trend in the context of high-latitude atmospheric circulation changes. J. Climate, 31, 3909-3920, https:// doi.org/10.1175/JCLI-D-17-0739.1.

Zheng, F., J. Li, R. T. Clark, and H. C. Nnamchi, 2013: Simulation and projection of the Southern Hemisphere annular mode in CMIP5 models. J. Climate, 26, 9860-9879, https://doi.org/ 10.1175/JCLI-D-13-00204.1. 